\title{
Biosynthesis of copper(II) oxide nanoparticles using Murayya koeniggi aqueous leaf extract and its catalytic activity in 4- nitrophenol reduction
}

\author{
Nurulhuda Raja Nordin, Mustaffa Shamsuddin* \\ Department of Chemistry, Faculty of Science, Universiti Teknologi Malaysia, 81310 UTM Johor Bahru, Johor, Malaysia \\ * Corresponding author: mustaffa@kimia.fs.utm.my
}

\section{Article history}

Received 15 January 2019

Revised 26 February 2019

Accepted 20 March 2019

Published Online 14 April 2019

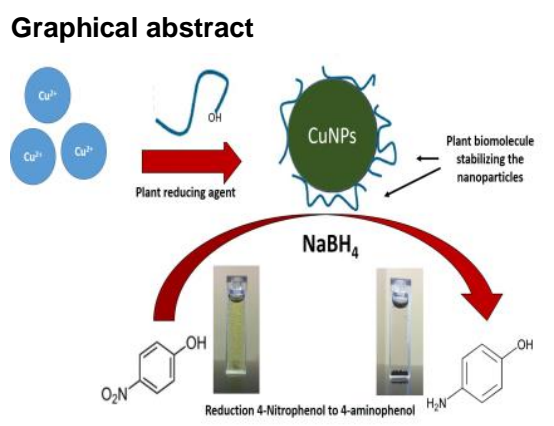

\begin{abstract}
Copper(II) oxide nanoparticles (CuO NPs) have a wide range of applications as catalysts. The natural abundance of copper and its relatively low cost make it a viable alternative to catalysts that made from expensive precious metals such as platinum and palladium. In this study, a rapid, simple and green method was developed for the synthesis of CuO NPs using an aqueous extract of Murayya koenigii leaves. Several parameters were optimized, namely, the volume of leaf extract, $\mathrm{pH}$, reaction temperature and reaction time. The optimum condition for the biosynthesis was obtained by using $3 \mathrm{~mL}$ of leaf extract; $10 \mathrm{~mL}$ of $5 \mathrm{mM} \mathrm{CuSO}_{4}$, at $\mathrm{pH} 11$, at room temperature. The biosynthesis was completed within 50 minutes. The synthesized CuO NPs were characterized using Ultraviolet-visible Spectroscopy (UV-Vis), Fourier Transform Infrared Spectroscopy (FTIR), X-ray Diffraction (XRD), and Transmission Electron Microscope (TEM) analyses. The UV-Vis absorption spectra confirmed the formation of CuO NPs with characteristic peak at $634 \mathrm{~nm}$. The FTIR spectroscopic analysis of the biosynthesized CuO NPs confirmed the surface adsorption of the bioactive components in the leaf extract that acted as the reducing agent and stabilizing agent for the metal nanoparticles. XRD analysis showed a series of diffraction peaks at $2 \theta$ of $32.5^{\circ}, 35.5^{\circ}, 38.6^{\circ}, 48.8^{\circ}, 53.4^{\circ}, 58.1^{\circ}, 61.5^{\circ}, 66.3^{\circ}, 68.0^{\circ}, 72.4^{\circ}$ and $75.0^{\circ}$, corresponding to (110), (002), (111), (202), (020), (202), (113), (311), (220), (311) and (222), respectively. From TEM images, CuO NPs were of spherical shape with a mean diameter of 8.4 $\mathrm{nm}$. The biosynthesized CuO NPs demonstrated good catalytic activities on the reduction of 4nitrophenol (4-NP) to 4-aminophenol (4-AP) in the presence of sodium borohydride, $\mathrm{NaBH}_{4}$ and could be reused three times without significant decreases in the catalytic activities.
\end{abstract}

Keywords: Copper oxide nanoparticles, biosynthesis, Murayya koenigii, catalytic properties

\section{INTRODUCTION}

Nanomaterials prepared from earth-abundant and inexpensive metals have attracted considerable attention because of their potential as promising alternatives to expensive noble metals that used as catalysts in many commercials chemical processes [1] . These metal nanoparticles often exhibit activity that different from the corresponding bulk materials due to their different sizes and shapes, resulting in unique catalytic, electronic, optical and other structural properties [2]. In this context, copper nanoparticles (Cu NPs) are attractive because of their natural abundance and low cost. Thus, the applications of $\mathrm{Cu}$ NPs that is based on the earth-abundant and inexpensive copper metal, have generated a great deal of interest in recent years, especially in the field of catalysis [3].

Currently, there are well-developed synthesis methods for $\mathrm{Cu}$ NPs, including thermal evaporation, sonochemical, sol-gel, hydrothermal, and electrochemical methods [4]. However, these methods are quite expensive and involved toxic reductants, polymers and solvents such as $\mathrm{NaBH}_{4}$, polyvinylpyrrolidone and ethylene gylcol which are potentially hazardous to the environment.

In recent years, the biogenic synthesis for metal nanoparticles synthesis have been gaining attention due to its simplicity and environmental friendly. Biogenic synthesis is also known as green chemical method in metal nanoparticles preparation, which employs non-toxic multi-functional reactants derived from natural, biological resources that ranging from microrganisms to plants [5]. Metal nanoparticles that synthesized from the biological route have good stability due to the presence of capping agents such as alkaloids, flavanoids and polyphenols, which are the major constituents presented in the natural resources.

Table 1 shows various biological methods that have been reported in synthesizing copper oxide nanoparticles (CuO NPs). The Murraya koenigii is commonly known as curry leaf or 'daun kari' in Malay. It belongs to the family Rutaceae [14]. Fresh and dried curry leaves are extensively used in Malaysian culinary practices for seasoning and flavouring dishes. Different parts of Murayya koenigii have been used in traditional Ayurveda medicine [15]. Previous phytochemical investigations on this plant revealed that the Murraya koenigii leaves are rich in phenolic acids (especially gallic acid) and flavonoids (especially myricetin, epicatechin, and quercetin) contents [16]. Rajendran et al reported that the essential oil from Murraya koenigii leaves showed anti-bacterial effect against bacteria Corynebacterium tuberculosis, Pseudomonas aeruginosa, Streptococcus pyogenes, Klebsiella pneumonia and Enterobacter aerogenes [17]. In addition, 
the naturally-occuring polypheols/flavanoids in Murraya koenigii have been reported to exhibit anti-tumor [18], anti-oxidant [19], [20], anti-inflammatory [21], anti-hyperglycemic [22], anti-histamnie [23], and hypoglycemic effects [24].

Table 1 Biological method in synthesis of CuO NPs

\begin{tabular}{lllc}
\hline $\begin{array}{l}\text { Biosynthesis } \\
\text { source }\end{array}$ & $\begin{array}{l}\text { Spesies } \\
\text { Fungi }\end{array}$ & $\begin{array}{l}\text { Morphology } \\
\text { and size }\end{array}$ & References \\
& $\begin{array}{l}\text { Stereum } \\
\text { hirsutum }\end{array}$ & $\begin{array}{l}\text { Spherical, } \\
4-5 \mathrm{~nm}\end{array}$ & {$[6]$} \\
\hline Bacteria & $\begin{array}{l}\text { E.coli } \\
\text { Spherical, } \\
5 \mathrm{~nm}\end{array}$ & {$[7]$} \\
\cline { 2 - 4 } & $\begin{array}{l}\text { Salmonella } \\
\text { typhimurium }\end{array}$ & $\begin{array}{l}\text { Spherical, } \\
49 \mathrm{~nm}\end{array}$ & {$[8]$} \\
\hline Plant/plant & $\begin{array}{l}\text { Drypetes } \\
\text { parts }\end{array}$ & $\begin{array}{l}\text { Spherical, } \\
\text { sepiaria (leaves } \\
\text { extract) }\end{array}$ & {$[9]$} \\
\hline & $\begin{array}{l}\text { Banana } \\
\text { (peel extract) }\end{array}$ & $\begin{array}{l}\text { Spherical, } \\
60 \mathrm{~nm}\end{array}$ & {$[10]$} \\
\cline { 2 - 4 } & $\begin{array}{l}\text { Abutilon indicum } \\
\text { (leaves extract) }\end{array}$ & $\begin{array}{l}\text { Spherical, } \\
16 \mathrm{~nm}\end{array}$ & {$[11]$} \\
\cline { 2 - 4 } & $\begin{array}{l}\text { Cassia } \\
\text { auriculata } \\
\text { (leaves extract) }\end{array}$ & $\begin{array}{l}\text { Spherical, } \\
23 \mathrm{~nm}\end{array}$ & {$[12]$} \\
\cline { 2 - 3 } & $\begin{array}{l}\text { Punica } \\
\text { granatum (peel } \\
\text { extract) }\end{array}$ & $\begin{array}{l}\text { Spherical, } \\
40 \mathrm{~nm}\end{array}$ & {$[13]$} \\
& & & \\
\hline
\end{tabular}

Nitro aromatic compounds such as nitrophenols, are common industrial nitrogen-containing aromatic organic compounds that are commonly exploited in the manufacturing of pharmaceuticals, plastics, dye, agriculture, etc. The direct discharge of these compounds as industrial wastes into the ecosystem is harmful to the biological system as well as human beings because these compounds are oftenly resistant to degradation under normal environmental conditions. Presence of these compounds in the ecosystem, even in small quantities, is highly undesirable and has drastic, adverse effects on the environment and human beings since many of these compounds possess environmental toxic, mutagenic and carcinogenic potentials [25].

The present study would describe an eco-friendly and simple synthesis route of $\mathrm{CuO}$ NPs by employing an abundantly available Murayya koenigii leaves aqueous extract as the reducing and stabilizing agent. The potential application of the biosynthesized $\mathrm{CuO}$ $\mathrm{NPs}$ as catalyst in the reduction of 4-nitrophenol (4-NP) to 4aminophenol (4-AP) (Scheme 1) in aqueous medium at room temperature in the presence of sodium borohydride, $\mathrm{NaBH}_{4}$ would also be investigated.<smiles>Nc1ccc(O)cc1</smiles>

Scheme 1. Reduction of nitrophenol to aminophenol

\section{EXPERIMENTAL}

\section{Materials}

Copper(II) sulphate pentahydrate $\left(\mathrm{CuSO}_{4} .5 \mathrm{H}_{2} \mathrm{O}\right)$, sodium hydroxide $(\mathrm{NaOH})$, 4-nitrophenol, 4-aminophenol and sodium borohydride, $\mathrm{NaBH}_{4}$ were purchased from Sigma-Aldrich. All other reagents were of analytical grades. Thin Layer Chromatography (TLC) analyses were performed using Merck pre-coated TLC plates (silica gel $60 \mathrm{GF} 254,0.25 \mathrm{~mm}$, Germany). All solutions were prepared in deionized water.

\section{Preparation of Murayya koenigii leaves extraction}

The collected fresh leaves of Murayya koenigii were washed thoroughly with deionized water to remove any dirt particles. The washed leaves were then air-dried. The cleaned and dried leaves were ground into powder using an electrical blender and sieved by using a 20 mesh sieve. In order to prepare the flavonoid rich extract, $2 \mathrm{~g}$ of the leaf powder was extracted with $200 \mathrm{~mL}$ of deionized water in a Soxhlet apparatus for six hours. After cooling, the leaf aqueous extract was stored at $5^{\circ} \mathrm{C}$ for further use. The prepared leaf extract with concentration of $1 \% \mathrm{w} / \mathrm{v}$ was employed throughout the study.

\section{Synthesis of CuO NPs}

As for the preparation of $\mathrm{CuO} \mathrm{NPs}, 1 \mathrm{~mL}$ of prepared leaf extract was added into $10 \mathrm{~mL}$ of $5 \mathrm{mM}$ aqueous copper(II) sulphate, $\mathrm{CuSO}_{4}$ and the $\mathrm{pH}$ of the mixture was adjusted to $\mathrm{pH} 11$ using $0.1 \mathrm{M}$ sodium hydroxide, $\mathrm{NaOH}$ solution. The mixture was stirred and the colour of the reaction mixture was gradually changed to dark brown, indicating the formation of $\mathrm{CuO}$ NPs. The formation of $\mathrm{CuO}$ NPs was monitored using Ultraviolet-visible spectroscopy (UV-Vis) for the detection of Surface Plasmon Resonance (SPR) band of CuO NPs after 60 minutes of reaction time. For optimization purposes, the biosynthesis of $\mathrm{CuO}$ NPs was carried out using different volumes of leaf extract, $\mathrm{pHs}$ and temperatures, while the time taken for the reaction to complete the bioreduction was recorded. The colloidal particles formed were centrifuged at $14800 \mathrm{rpm}$ for 20 minutes and the obtained precipitate was washed with deionized water and then dried in the desiccator for further use.

\section{Characterization of CuO NPs}

The biosynthesized $\mathrm{CuO}$ NPs were characterized using UV-vis and Fourier transform infrared (FTIR) spectroscopies, X-ray diffraction (XRD) and Transmission Electron Microscope (TEM) analytical methods. UV-vis spectral analysis was recorded on a Shimadzu-1800 double-beam spectrophotometer to ensure the formation of nanoparticles. The shape and size of synthesized $\mathrm{CuO}$ NPs were identified by TEM images using JEOL JEM-2000 EX instrument, operated at an accelerating voltage of $100 \mathrm{kV}$. FTIR analysis was carried out to identify the functional group of the biocapping agents on the $\mathrm{CuO} \mathrm{NP}$ surfaces. FTIR spectra of the synthesized samples were recorded on a Perkin Elmer 1600 FTIR spectrometer in the spectral range of $4000 \mathrm{~cm}^{-1}$ to $400 \mathrm{~cm}^{-1}$ using potassium bromide $(\mathrm{KBr})$ pressed disk technique. XRD analysis was done using X-ray diffractometer (D/tex Ultra 250 SmartLab diffractometer, Rigaku, Japan) with $\mathrm{Cu} K \alpha$ radiation $(\lambda=0.154 \mathrm{~nm})$ in the $2 \theta$ range from $10^{\circ}$ to $90^{\circ}$. Prior to XRD analysis, the CuO NPs were calcined at $600^{\circ} \mathrm{C}$ for 5 hours in order to yield a fine, black $\mathrm{CuO}$ NPs which were stored in an airtight container.

\section{Catalytic activity of CuO NPs}

In a typical reaction procedure, freshly prepared $\mathrm{NaBH}_{4}(300 \mu \mathrm{L}$, $100 \mathrm{mM})$ was added into $4-\mathrm{NP}(3 \mathrm{~mL}, 0.05 \mathrm{mM})$ in a quartz cuvette. Both solutions were prepared using distilled water. Then, $1 \mathrm{mg}$ of $\mathrm{CuO}$ NPs catalyst was added into the mixture. The colour of the solution would be faded as the reaction was proceeded. The reaction was monitored using UV-vis spectroscopy in which the absorbance of the 4-nitrophenolate ion was recorded every 1.5 minute intervals in the scanning range between $200 \mathrm{~nm}$ and $500 \mathrm{~nm}$. After completing the reaction, the mixture was centrifuged at $14800 \mathrm{rpm}$ for 20 minutes to separate the catalyst for recyclability test. The separated catalyst was washed twice with distilled water. The percentage of conversion from 4-NP to 4-AP was determined by calculation from the absorbance data.

\section{Purification and characterization of 4-AP}

For the purification of 4-AP, the reaction was scaled up in the ratio of 4-NP $(3.75 \mathrm{mM}, 50 \mathrm{~mL}), \mathrm{NaBH}_{4}(750 \mathrm{mM}, 50 \mathrm{~mL})$, with 5 $\mathrm{mg}$ of $\mathrm{CuO}$ NPs catalyst used. The mixture was stirred until the reaction mixture had turned into colourless. After completion of the reaction, the catalyst was separated by centrifugation and hydrochloric acid, $\mathrm{HCl}$ solution $(2 \mathrm{M}, 10 \mathrm{~mL})$ that was added to quench the 
reaction. Into this solution, ethyl ether was added and a liquid-liquid extraction was conducted. The extraction step was repeated three times. Ethyl ether fractions containing 4-AP were combined and water was removed using anhydrous sodium sulphate, $\mathrm{Na}_{2} \mathrm{SO}_{4}$. Then, ethyl ether was evaporated using rotary evaporator. A silica gel column chromatography was performed by eluting with solvent composed of hexane:ethyl acetate in the ratio of 1:2. Each eluent was loaded on a thin layer chromatography, TLC plate together with 4-AP standard. The fractions containing 4-AP were combined and solvents were evaporated. Both standard 4-AP from a commercial source and purified 4-AP from the above procedure were characterized by ${ }^{1} \mathrm{H}-$ NMR.

\section{Recyclability test}

Recycle experiments were performed to test the reusability of the $\mathrm{CuO}$ NPs catalyst. The recyclability test was performed by carrying out the reaction under the same conditions as the model reaction. After the first run, the catalyst was separated from the reaction mixture by centrifugation. The catalyst was washed twice with deionized water to remove any residue from the catalytic reaction mixture. The separated catalyst was vacuum dried in a desiccator and reused again. In the subsequent run, the same amount of 4-NP and a freshly prepared $\mathrm{NaBH}_{4}$ were used. The percentage of conversion of the 4-nitrophenolate ion was calculated and compared with the first run.

\section{RESULTS AND DISCUSSION}

\section{Biosynthesis, optimization and characterization CuO NPs}

The formation of $\mathrm{CuO}$ NPs was preliminary monitored by UV-Vis spectroscopy, followed by further characterization using FTIR spectroscopy, TEM and XRD analytical data. The formation of $\mathrm{CuO}$ NPs was clearly observed by the colour change from pale yellow to dark brown upon the addition of $1 \mathrm{~mL}$ of $1 \%$ Murayya koenigii leaf extract into the $10 \mathrm{~mL}$ of $5 \mathrm{mM} \mathrm{CuSO}_{4}$ solution (Fig. 1(a)). The $\mathrm{pH}$ of the reaction was adjusted to $\mathrm{pH} 11$ by using $\mathrm{NaOH}$ solution because the $\mathrm{pH}$ of solution played a vital role in the $\mathrm{CuO}$ NPs formation [30]. Fig. 1(b) shows the UV-Vis absorption spectra of the leaf extract and the colloidal solution after 60 minutes of reaction time. The appearance of an absorption maximum at $\lambda_{\max } 670 \mathrm{~nm}$ could be attributed to the surface plasmon resonance (SPR) band of the $\mathrm{CuO}$ NPs, thus indicating the successful formation of CuO NPs. This result was in agreement with a similar study which reported on the biosynthesis of $\mathrm{CuO}$ NPs using aloe vera leaf extract [31].
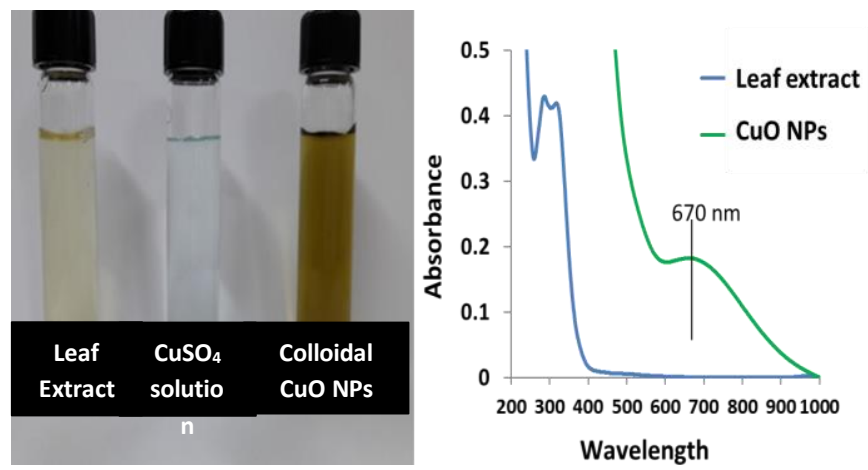

Fig. 1 (a) Photographic image of colour change during the course of the reaction and (b) UV-Vis spectra of leaf extract and colloidal CuO NPs.

Fig. 2 shows a schematic diagram of a proposed mechanism for the biosynthesis and stabilizing of the CuO NPs. The initial steps were involved the reduction of $\mathrm{Cu}^{2+}$ ions and followed by nucleation of the reduced metal atoms. The growth steps were referred to the spontaneous coalescence of the small adjacent nanoparticles into particles of a larger size, followed by capping with the plant biomolecules (polyphenols).

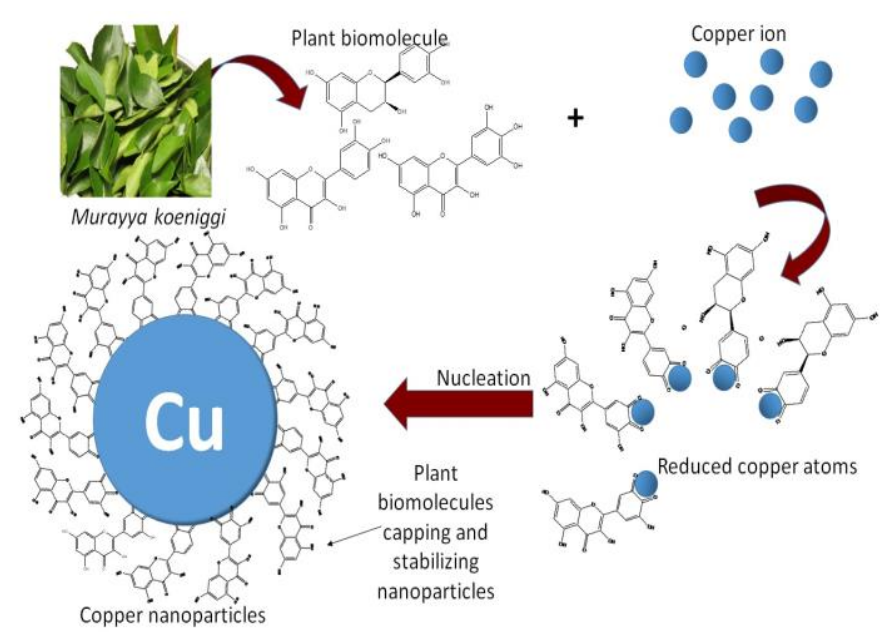

Fig. 2 Proposed mechanism for the formation and stabilization of $\mathrm{CuO}$ NPS.

Biosynthesis conditions, such as volume of leaf extract, $\mathrm{pH}$, and temperature are among the significant influencing factors on the size of nanoparticles [26]. In this study, an optimization approach for synthesizing $\mathrm{CuO}$ NPs with uniform shape, smaller particle size and narrow size distributions was reported. The intensity and the width of the SPR absorption band are depended on the size of the metal nanoparticles [27]. In order to get the optimum amount of leaf extract for the reduction of $\mathrm{Cu}^{2+}$ ion, the volume optimization of Murayya koenigii leaf extract was studied. Fig. 3(a) shows the UV-Vis spectra for $\mathrm{CuO}$ NPs formation after 60 minutes of reaction time using a fixed $\mathrm{CuSO}_{4}$ concentration $(5 \mathrm{mM})$ with different volumes of Murayya koenigii leaf extract added. A blue shift in the wavelength from $\lambda_{\max }$ $670 \mathrm{~nm}$ to $658 \mathrm{~nm}$ was observed with the increase in amount of leaf extract ( $3 \mathrm{~mL})$, which could be explained due to the basis of increased nucleation rate in the biosynthesis process. As a conclusion, greater amount of polyphenol would increase the nucleation rate and lead to the generation of smaller $\mathrm{CuO}$ NPs in the solution. However, with further increase in the leaf extract volume to $4 \mathrm{~mL}$, the plasmonic band in the visible region became broader. The broadness of the absorption spectra could be attributed to the wide size distribution of $\mathrm{CuO}$ NPs. This might be due to the collision between smaller nanoparticles which then led to particle growth during the growth phase.

The work reported by Rajesh et al showed that the $\mathrm{pH}$ in aqueous media has an influence on the progress of the copper reduction reaction [28]. The biosynthesis of $\mathrm{CuO}$ NPs using $3 \mathrm{~mL}$ leaf extract and $10 \mathrm{~mL}$ of $5 \mathrm{mM} \mathrm{CuSO}_{4}$ was carried out at different $\mathrm{pH}$ values, namely $\mathrm{pH} 8,9,10$, and 11 (Fig. 3(b). Without any $\mathrm{pH}$ modification, after mixing the leaf extract and $\mathrm{CuSO}_{4}$ solution, the $\mathrm{pH}$ value of about 5.4 was recorded. At this acidic $\mathrm{pH}$, the particles size was seemed to be larger than at the basic $\mathrm{pH}$, as a red shift $\left(\lambda_{\max }=770 \mathrm{~nm}\right)$ was clearly observed in the SPR spectra. As the $\mathrm{pH}$ was increased from $\mathrm{pH} 8$ to $\mathrm{pH} 10$, it was observed that there was no significant difference on the intensity and the position of the SPR band at $\lambda_{\max }$ $660 \mathrm{~nm}$. Meanwhile, at $\mathrm{pH} \mathrm{11}$, the blue shift in SPR peak position at $\lambda_{\max } 634 \mathrm{~nm}$ could be attributed to the decrease in the particle size. This result was in good agreement with the previous study on the biosynthesis of $\mathrm{CuO}$ NPs at optimum $\mathrm{pH}$ of $\mathrm{pH} 11$ [29]. The role of $\mathrm{pH}$ on nanoparticles synthesis could be seen in its effect on the capping and stabilizing abilities, and subsequently the growth of the nanoparticles [30]. The presence of $\mathrm{OH}^{-}$ion in alkaline $\mathrm{pH}$ environment might enhance the reducing and stabilizing capabilities of the biomolecules in the leaf extract. The $-\mathrm{CHO}$ group on biomolecules was oxidized into $-\mathrm{COO}^{-}$, offering stability and better capping agent for the generated metal particles in the presence of $\mathrm{OH}^{-}$ ion [31]. 


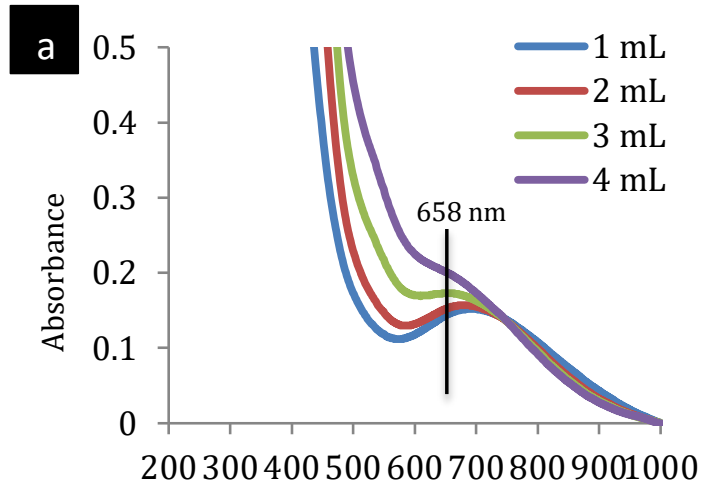

Wavelength (nm)
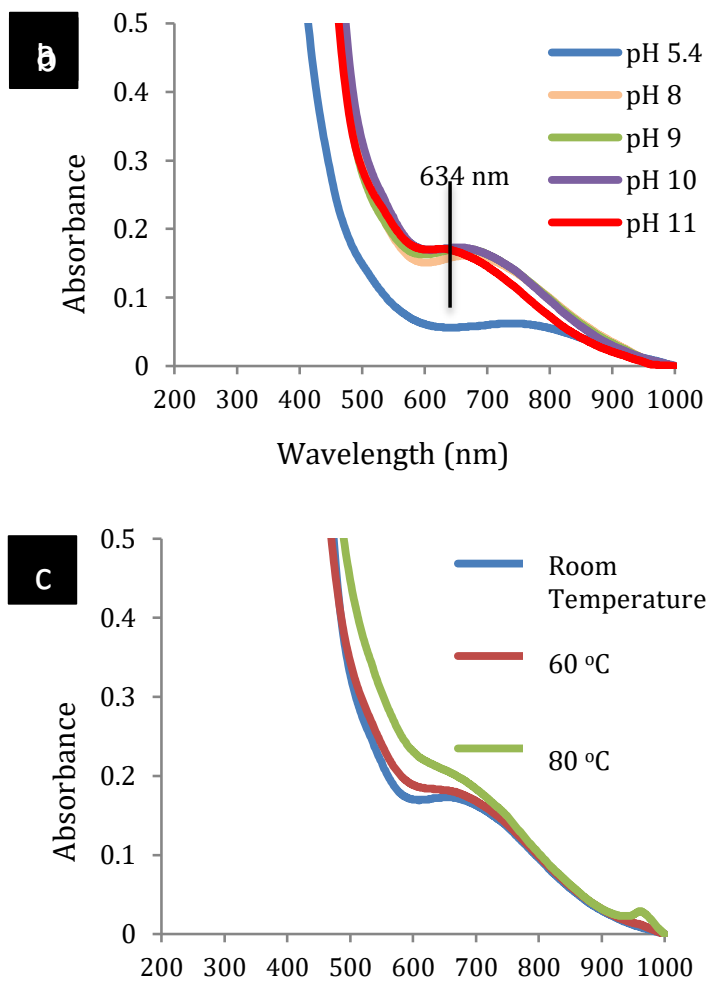

Wavelength (nm)

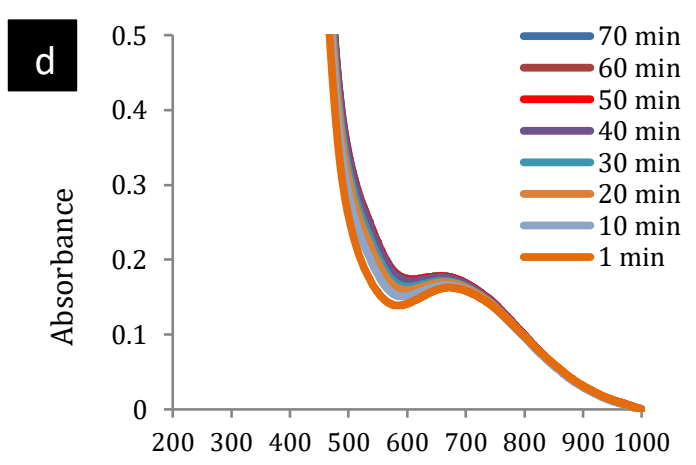

Wavelength $(\mathrm{nm})$

Fig. 3 UV-Vis of bioreduction of CuO NPs at different (a) volume of leaf extract; (b) $\mathrm{pH}$; (c) temperature and (d) reduction time

The effect of temperature on the biosynthesis of CuO NPs was also studied for the $3 \mathrm{~mL}$ volume of leaf extract and $10 \mathrm{~mL}$ of $5 \mathrm{mM}$ $\mathrm{CuSO}_{4}$ solution at $\mathrm{pH} 11$ at different temperatures, namely, at room temperature, $60^{\circ} \mathrm{C}$ and $80^{\circ} \mathrm{C}$ (Fig. 3(c)). Previous work revealed that temperature of the reaction would affect the size and morphology of the synthesized nanoparticles due to the fact that the nucleation and growth of nanoparticles were depended on the temperature [32]. The studies on the physico-chemical conditions optimization during biosynthesis by Kumari reported that different temperatures would produce different nanoparticles morphologies such as prism, pentagon and hexagon [33]. In this study, as revealed by the UV-Vis spectra shown in Figure $3(\mathrm{c})$, both room temperature and $60^{\circ} \mathrm{C}$ produced similar size of nanoparticles since the plasmonic bands were appeared at the same $\lambda_{\max }$. However, as the temperature was increased to $80^{\circ} \mathrm{C}$, the formation of a new peak near the infra-red region was appeared which indicated to the anisotropic growth of $\mathrm{CuO}$ NPs. Thus, the biosynthesis of $\mathrm{CuO}$ NPs that carried out at room temperature would be the best condition as it did not show any difference in term of the nanoparticle size obtained as compared to those that performed at higher temperature $\left(60^{\circ} \mathrm{C}\right)$.

Furthermore, the time for complete formation of $\mathrm{CuO}$ NPs was also investigated. The UV-Vis spectra for the colloidal CuO NPs against time were shown in Fig. 3(d). Meanwhile, the plot of absorbance at $\lambda_{\max }$ versus time for CuO NPs formation was illustrated in Fig. 4, showing that the biosynthesis has reached saturation within 50 minutes. Thus, it was concluded that the formation of $\mathrm{CuO}$ NPs was completed within 1 hour.

FTIR spectral analysis was conducted to identify the possible functional groups of the biomolecules presented in the Muraya koenigii leaf powder that would be responsible for the reduction of $\mathrm{Cu}^{2+}$ ion to $\mathrm{CuO}$ NPs. The FTIR spectrum of Muraya koenigii leaf powder was shown in Fig. 5(a) and revealed characteristic bands for $\mathrm{O}-\mathrm{H}$ stretching vibrations at $3396 \mathrm{~cm}^{-1}$ that could originate from alcohol or phenol functionality. The weak absorption bands were observed at $2944 \mathrm{~cm}^{-1}$ that corresponded to C-H stretching in alkanes, while strong stretching vibration of $\mathrm{C}=\mathrm{O}$ was observed at $1606 \mathrm{~cm}^{-1}$. The medium intesity band observed at $1400 \mathrm{~cm}^{-1}$ was assigned to $\mathrm{C}-\mathrm{C}$ stretching in aromatic groups. The appearance of these functional groups might be attributed to the presence of biomolecules such as polyphenolic acids and flavonoids in the leaf extract powder. By comparison, the FTIR spectrum of the $\mathrm{CuO}$ NPs powder showed almost similar pattern as the FTIR spectrum of the Murayya koenigii leaf powder, which probably suggesting the presence of flavonoids and polyphenolic acids on the surface of the CuO NPs (Fig. 5(b)). These phytochemicals were not only acted as reducing agent but also as capping agent which helped to minimize the agglomeration of NPs by controlling the morphology and stabilizing the NPs. The phenolic hydroxyl group of phytochemicals was formed into metal-phenolate complex when hydroxyl group was bound with metal by chelating effect [34]. These complexes would undergo direct decomposition at $600^{\circ} \mathrm{C}$ and lead to the formation of $\mathrm{CuO}$ NPs.

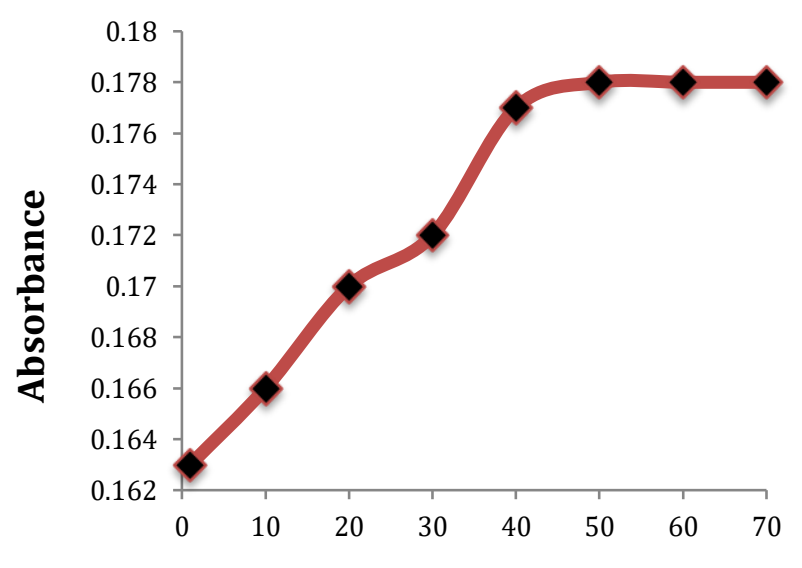

Time (min)

Fig. 4 Absorption at $\lambda_{\max }$ versus time for CuO NPs formation 


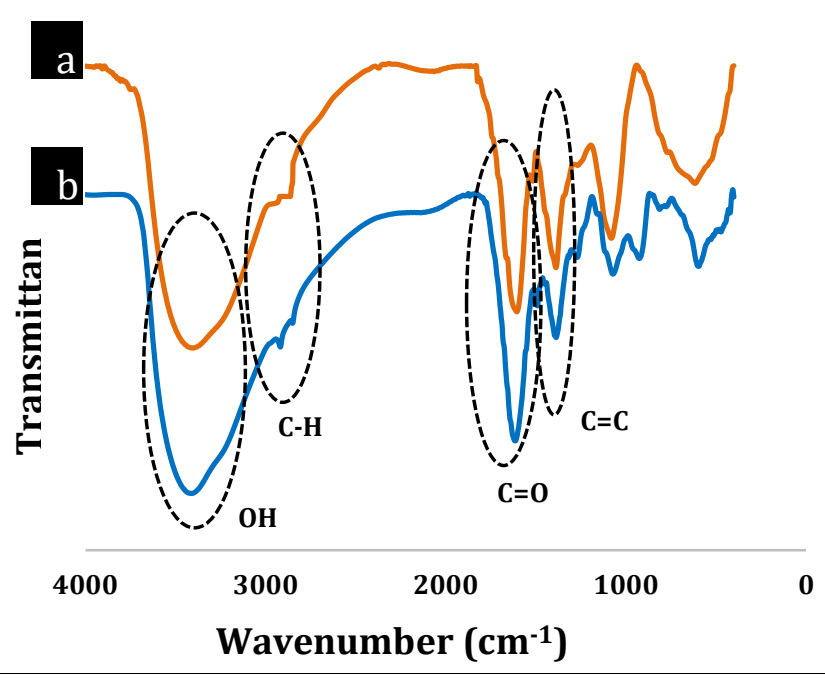

Fig. 5 FTIR spectra of (a) Murayya koenigii Leaf Extract Powder and; (b) CuO NPs Powder

The CuO NPs biosynthesized from Murayya koenigii leaf extract were confirmed by the characteristic peaks observed in the XRD pattern, as shown in Fig. 6. XRD analysis showed intense peaks at $32.5^{\circ}, 35.5^{\circ}, 38.6^{\circ}, 48.8^{\circ}, 53.4^{\circ}, 58.1^{\circ}, 61.5^{\circ}, 66.3^{\circ}, 68.0^{\circ}, 72.4^{\circ}$ and $75.0^{\circ}$, which corresponding to (110), (002), (111), (202), (020), (202), (113), (311), (220), (311) and (222), respectively. The observed diffraction reflections were comparable with JCPDS No. 45-0937 and attributed to bulk $\mathrm{CuO}$ materials. All diffraction peaks could be indexed as the typical monoclinic structure and no extra diffraction peaks of other phases were observed. Moreover, the well-defined and sharp $\mathrm{CuO}$ reflections in the observed XRD patterns were confirmed the well-crystalline nature of $\mathrm{CuO}$ NPs.

Fig. 7 demonstrates the TEM images of the $\mathrm{CuO}$ NPs at different magnifications which clearly showed spherical morphology of the $\mathrm{CuO}$ NPs biosynthesized from Murayya koenigii plant. The mean particle diameter, measured by image $\mathrm{J}$ software from 50 particles counts for CuO NPs was estimated to be $8.4 \mathrm{~nm}$.

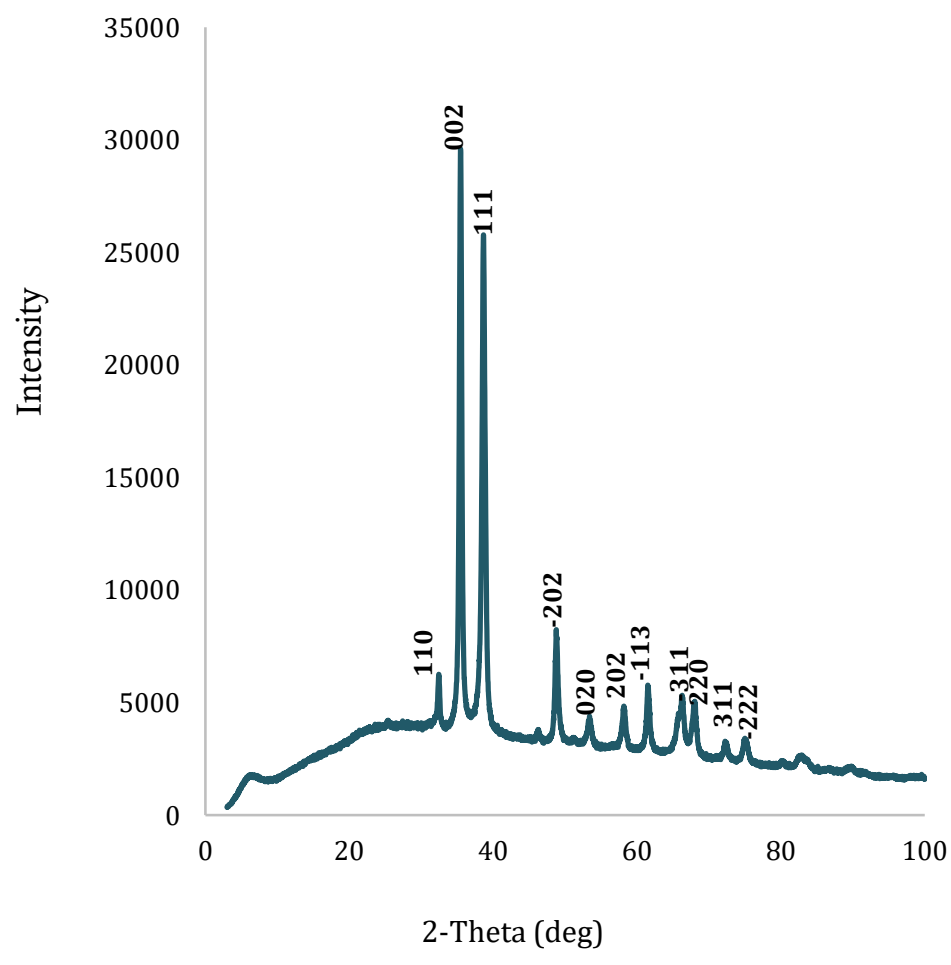

Fig. 6 XRD pattern of biosynthesized CuO NPs.

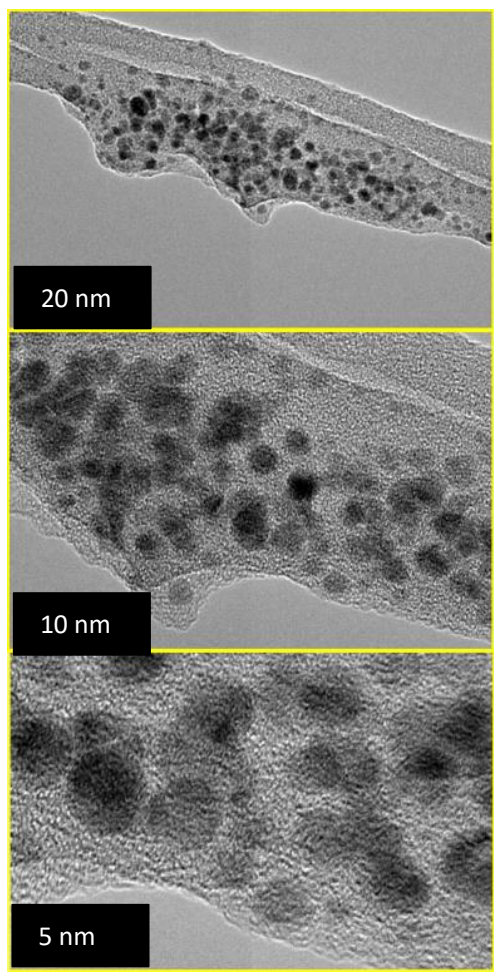

Fig. 7 TEM images of CuO NPs at different magnifications (20, 10 and $5 \mathrm{~nm})$.

\section{Catalytic activity test of 4-NP reduction reaction}

The 4-NP reduction to 4-AP was generally selected as a model reaction for evaluating the catalytic activity of $\mathrm{CuO}$ NPs. This reaction could be easily monitored by UV-vis spectroscopy. In this study, the catalytic activity of the biosynthesized $\mathrm{CuO}$ NPs in the reduction of 4-NP at room temperature in aqueous medium was evaluated. When 4-NP was mixed with $\mathrm{NaBH}_{4}$, the solution became yellowish and has a maximum absorbance at $400 \mathrm{~nm}$ due to the formation of 4-nitrophenolate anion. Without the addition of $\mathrm{CuO}$ NPs as a catalyst, the peak of 4-nitrophenolate anion at $400 \mathrm{~nm}$ did not change even after 1 hour of reaction time (Fig. 8(a)). Upon the addition of $\mathrm{CuO}$ NPs, the peak at $400 \mathrm{~nm}$ was started to decrease while a new peak at $300 \mathrm{~nm}$ was simultaneously appeared (Fig. 8(b)). The new peak at $300 \mathrm{~nm}$ was exhibited to an absorbance corresponding to the reaction product of 4-AP. The reaction was completed within 9 minutes, in which there were no more changes in 4-nitrophenolate absorbance observed.

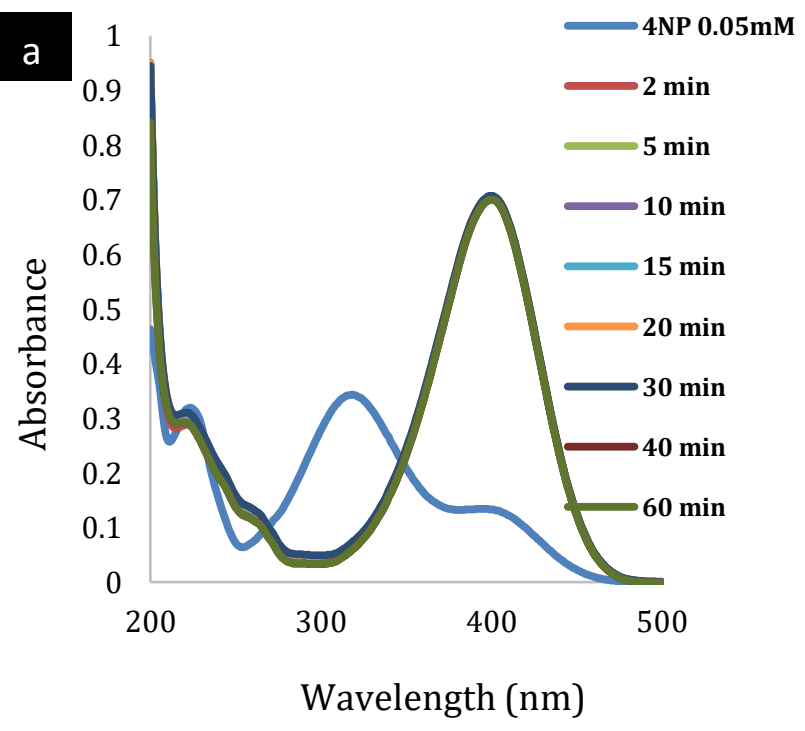




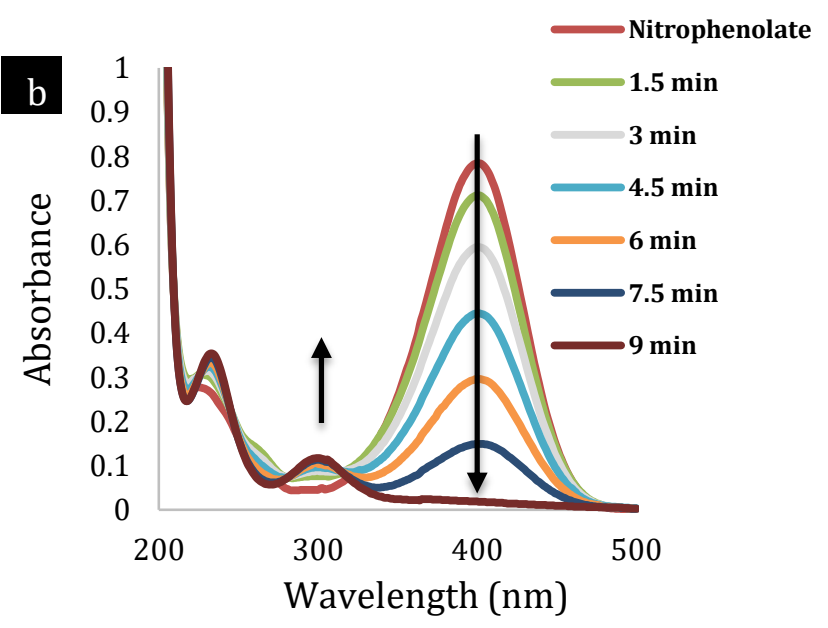

Fig. 8 UV-Vis spectra for the reduction of 4-NP (a) without Catalyst; (b) with CuO NPs Catalyst.

For quantitative analysis, a calibration curve was constructed with 4-NP solutions and a linear regression equation of $y=12.968 x+$ 0.0087 with correlation coefficient of 0.9995 in the concentration range of $0.01-0.09 \mathrm{mM}$ was obtained (Fig. 9(a)). Based on this equation, the conversion yield of 4-NP to 4-AP was measured to be $95.8 \%$. A reaction rate was measured from the plot between $\ln \left(\mathrm{A}_{t} / \mathrm{A}_{0}\right)$ versus time (sec). Herein, the $4-\mathrm{NP}$ concentrations at time $\mathrm{t}=0$ and time, $t$ were expressed as $A_{0}$ and $A_{t}$, respectively. It was shown that there was a linear relationship between $\ln \left(\mathrm{A}_{t} / \mathrm{A}_{0}\right)$ and time $(\mathrm{sec})$, suggesting that the reaction was followed a pseudo-first-order kinetics with a rate constant value of $9.2 \times 10^{-3} \mathrm{~s}^{-1}$ (Fig. 9(b)).

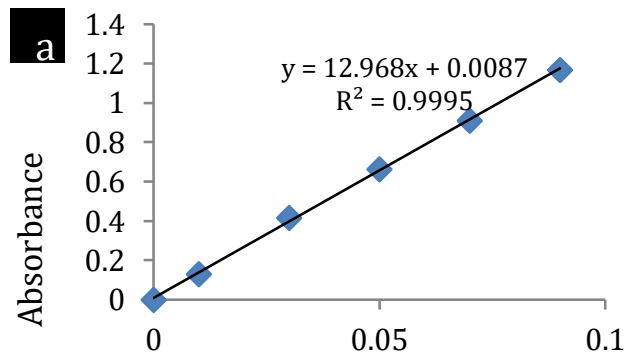

Concentration (mM)

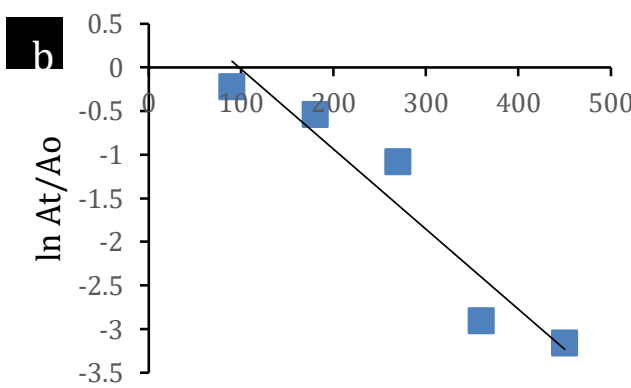

Time (s)

Fig. 9 (a) Calibration curve of 4-NP at different concentrations $(0.01$ $\mathrm{mM}-0.09 \mathrm{mM}$ ) (b) In $A_{t} / A_{0}$ vs time for 4-NP reduction reaction.

\section{Product purification and characterization}

For the purification of the 4-NP reduction product, the reaction was scaled up with 4-NP $(3.75 \mathrm{mM}, 50 \mathrm{~mL}), \mathrm{NaBH}_{4}(750 \mathrm{mM}, 50$ $\mathrm{mL}$ ), and $\mathrm{CuO}$ NPs catalyst ( $5 \mathrm{mg}$ ). After the work-up procedures, the isolated product was purified by silica gel column chromatography and its structure was determined by ${ }^{1} \mathrm{H}-\mathrm{NMR}$ spectroscopy. In comparison with the standard 4-AP (Fig. 10(a)), the purified product was confirmed to be 4-AP (Fig. 10(b)).
4-Aminophenol (standard):

${ }^{1} \mathrm{H}$ NMR (400 MHz, DMSO): $\delta \mathrm{H}=8.37(\mathrm{~s}, 1 \mathrm{H}), 6.50(\mathrm{~d}, J=8.4 \mathrm{~Hz}$, $2 \mathrm{H}), 6.44(\mathrm{~d}, J=8.4 \mathrm{~Hz}, 2 \mathrm{H}), 4.39$ (s, 2H).

4-Aminophenol (purified):

${ }^{1} \mathrm{H}$ NMR (400 MHz, DMSO): $\delta \mathrm{H}=8.36(\mathrm{~s}, 1 \mathrm{H}), 6.49(\mathrm{~d}, J=8.4 \mathrm{~Hz}$, $2 \mathrm{H}), 6.42(\mathrm{~d}, J=8.4 \mathrm{~Hz}, 2 \mathrm{H}), 4.39(\mathrm{~s}, 2 \mathrm{H})$.

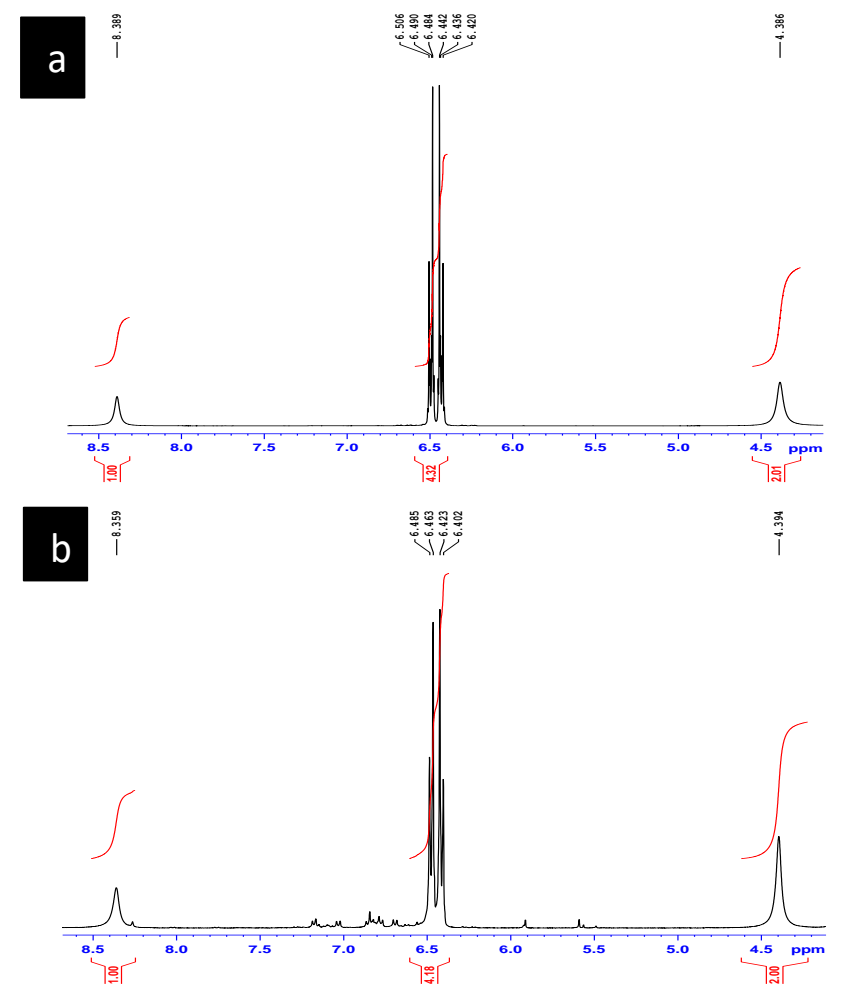

Fig. $10{ }^{1} \mathrm{H}$-NMR spectra of (a) standard 4-AP (b) purified product (4-AP)

\section{Recyclability test}

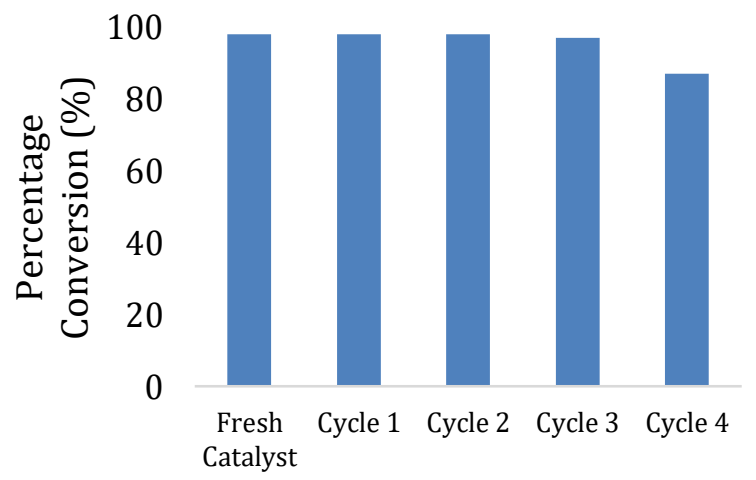

Fig. 11 Recycle test of CuNPs catalyst (Reaction conditions: $1 \mathrm{mg}$ of 3 $\mathrm{mL}$ 4-NP (0.05 mM), $300 \mu \mathrm{L} \mathrm{NaBH4}(100 \mathrm{mM})$, room temperature, 15 minute).

The recyclability of the CuO NPs catalyst for reduction of 4-NP organic molecule was also investigated by applying the used $\mathrm{CuO}$ NPs catalyst for successive cycles of reaction. Used catalyst was collected by centrifugation and washed thoroughly with deionized water to remove residues of catalytic reaction for every subsequent run. The recyclability test results for the $\mathrm{CuO}$ NPs catalyst were illustarted in Fig. 11. The catalytic experiments were carried out under similar conditions, indicating that CuNPs have a relatively good activity even in the 3rd cycle. It was shown that the CuNPs could maintain their catalytic activity within $98 \%$ conversion after three cycles, indicating that there was no significant loss of catalytic activity. In cycle 4 , a slight decrease in conversion of about $10 \%$ was observed. This could be probably due to the loss of catalyst mass during the catalyst recovery process. 


\section{CONCLUSION}

The green synthesis was successfully employed to synthesize $\mathrm{CuO}$ NPs from the leaves of Murraya koenigii plant in aqueous medium. This method was simple, low cost and eco-friendly without using any toxic chemicals. The synthesized $\mathrm{CuO}$ NPs were mostly spherical in shape with mean particle size of about $8 \mathrm{~nm}$ and possessed well crystalline nature which perfectly matched to monoclinic structure of bulk $\mathrm{CuO}$. The biosynthesized $\mathrm{CuO}$ NPs were utilized as catalyst for the reduction of 4-NP to 4-AP. The product was obtained in excellent yield and the catalyst could be recycled up to four cycles with almost consistent activity.

\section{ACKNOWLEDGEMENT}

This work was financially supported by the Ministry of Higher Education Malaysia and Universiti Teknologi Malaysia through research funding under GUP Vot 12H53 and FRGS Vot 4F779.

\section{REFERENCES}

[1] M. B. Gawande, A. Goswami, F.X. Felpin, T. Asefa, X. Huang, R. Silva, X. Zou, R. Zboril, R.S. Varma, "Cu and Cu-based nanoparticles: Synthesis and applications in catalysis," Chem. Rev., vol. 116, no. 6, pp. 3722-3811, 2016.

[2] S. A. Dahoumane, C. Jeffryes, M. Mechouet, and S. N. Agathos, "Biosynthesis of inorganic nanoparticles: A fresh look at the control of shape, size and composition," Bioeng., vol. 4, no. 14, pp. 1-16, 2017.

[3] K. Zhou, R. Wang, B. Xu, and Y. Li, "Synthesis , characterization and catalytic properties of $\mathrm{CuO}$ nanocrystals with various shapes," Nanotechnol., vol. 17, pp. 3939-3943, 2006.

[4] T. H. Tran and V. T. Nguyen, "Copper oxide nanomaterials prepared by solution methods, some properties, and potential applications: A brief review," Int. Sch. Res. Notices., vol. 2014, 2014.

[5] M. Hasan, I. Ullah, H. Zul, K. Naeem, A. Iqbal, and H. Gul, "Biological entities as chemical reactors for synthesis of nanomaterials: Progress challenges and future perspective," Mater. Today Chem., vol. 8, pp. 13$28,2018$.

[6] R. Cuevas, N. Durán, M. C. Diez, G. R. Tortella, and O. Rubilar, "Extracellular biosynthesis of copper and copper oxide nanoparticles by Stereum hirsutum, a native white-rot fungus from chilean forests," $J$. Nanomater., vol. 2015, no. November, 2015.

[7] H. R. Ghorbani, I. Fazeli, and A. A. Fallahi, "Biosynthesis of copper oxide nanoparticles using extract of E.coli," Orient. J. Chem., vol. 31, no. 1, pp. 515-517, 2015

[8] H. R. Ghorbani, "Extracellular synthesis of copper nanoparticles using culture supernatants of Salmonella typhimurium," Orient. J. Chem., vol. 31, no. 1, pp. 527-529, 2015.

[9] P. Narasaiah, B. K. Mandal, and N. C. Sarada, "Biosynthesis of copper oxide nanoparticles from Drypetes sepiaria leaf extract and their catalytic activity to dye degradation," IOP Conf. Ser. Mater. Sci. Eng., vol. 263, no. 2, 2017.

[10]M. Aminuzzaman, L. M. Kei, and W. H. Liang, "Green synthesis of copper oxide $(\mathrm{CuO})$ nanoparticles using banana peel extract and their photocatalytic activities," Am. Inst. Phys., vol. 20016, 2017.

[11]F. Ijaz, S. Shahid, S. A. Khan, W. Ahmad, and S. Zaman, "Green synthesis of copper oxide nanoparticles using Abutilon indicum leaf extract: Antimicrobial, antioxidant and photocatalytic dye degradation activitie," Trop. J. Pharm. Res., vol. 16, no. 4, pp. 743, 2017.

[12]L. B. Shi, P. F. Tang, W. Zhang, Y. P. Zhao, L. C. Zhang, and H. Zhang, "Green synthesis of $\mathrm{CuO}$ nanoparticles using Cassia auriculata leaf extract and in vitro evaluation of their biocompatibility with rheumatoid arthritis macrophages," Trop. J. Pharm. Res. January, vol. 16, no. 1, pp. 185-192, 2017.

[13] A. Y. Ghidan, T. M. Al-Antary, and A. M. Awwad, "Green synthesis of copper oxide nanoparticles using Punica granatum peels extract: Effect on green peach Aphid," Environ. Nanotechnol. Monit. Manage., vol. 6, pp. 95-98, 2016.

[14]B. Noolu and A. Ismail, "Anti-proliferative and proteasome inhibitory activity of Murraya koenigii leaf extract in human cancer cell lines,"
Phytomed., vol. 2, pp. 1-9, 2015.

[15] M. Jain, R. Gilhotra, R. Pal, and J. Mittal, "Curry Leaf ( Murraya koenigii ): A spice with medicinal property," MOJ Biol. Med. Prop., vol. 2, no. 3, 2017.

[16]A. Ghasemzadeh, H. Z. E. Jaafar, A. Rahmat, and T. Devarajan, "Evaluation of bioactive compounds, pharmaceutical quality, and anticancer activity of curry leaf (Murraya koenigii L.)," Evidence-Based Complement. Altern. Med., vol. 2014, pp. 1-8, 2014.

[17] M. P. Rajendran, B. B. Pallaiyan, and N. Selvaraj, "Chemical composition, antibacterial and antioxidant profile of essential oil from Murraya koenigii (L.) leaves.," Avicenna J. phytomed., vol. 4, no. 3, pp. 200-14, 2014.

[18]S. K. Yeap, N. Abu, N.E. Mohamad, B. K. Beh, W.Y., Ho, S. Ebrahimi, H. M. Yusof, H. Ky, S. W. Tan, N. B. Alitheen, "Chemopreventive and immunomodulatory effects of Murraya koenigii aqueous extract on 4T1 breast cancer cell-challenged mice," BMC Complement. Altern. Med., vol. 15, no. 1, pp. 1-10, 2015.

[19]A. N. Waghmare, S. V Tembhurne, and D. M. Sakarkar, "Antioxidant Properties of Murraya koenigii ( L .) Fruits," Am. J. Phytomed. Clin. Ther., vol. 3, no. 5, pp. 403-416, 2015 .

[20]R. S. Tomar, S. Banerjee, and S. Kaushik, "Assessment of antioxidant activity of leaves of Murraya koenigii extracts and it' $\mathrm{s}$ comparative efficacy analysis in different solvents," Pharm. Sci. Res., vol. 9(3), no. March, pp. 7-11, 2017.

[21] Y. Nalli, V. Khajuria, S. Gupta, P. Arora, S. Riyaz-Ul-Hassan, Z. Ahmed and A., Ali., "Four new carbazole alkaloids from Murraya koenigii that display antiinflammatory and antimicrobial activities," Org. Biomol. Chem., vol. 14, no. 12, pp. 3322-3323, 2016.

[22]I. M. Al-Ani, R. I. Santosa, M. H. Yankuzo, A. K. Saxena, and K. S. Alazzawi, "The Antidiabetic Activity of Curry Leaves 'Murraya Koenigii' on the glucose levels, kidneys, and islets of langerhans of rats with streptozotocin induced diabetes," Makara J. Heal. Res., vol. 21, no. 2, pp. 54-60, 2017.

[23]H. M. Qureshi, M. O. Omer, M. Ashraf, A. Bukhsh, M. A. Chaudhry, and M. S. Imran, "Evaluation of antihistaminic and anticholinergic activities of Murraya koenigii linn.," Pak. Vet. J., vol. 35, no. 2, pp. 242-244, 2015.

[24]A. N. Waghmare, S. V Tembhurne, and D. M. Sakarkar, "Hypoglycemic effects of fruit extracts of murraya koenigii (1) in streptozotocin induced diabetic rats," Asian J. Pharm. Res. Dev., vol. 3, no. 5, pp. 1-8, 2015.

[25]P. Kovacic and R. Somanathan, "Nitroaromatic compounds: Environmental toxicity, carcinogenicity, mutagenicity, therapy and mechanism," J. Appl. Toxicol., vol. 34, no. 8, pp. 810-824, 2014.

[26] J. K. Patra and K. H. Baek, "Green nanobiotechnology: factors affecting synthesis and characterization techniques," J. Nanomater., vol. 2014, 2014.

[27] M. A. Garcia, "Surface plasmons in metallic nanoparticles : Fundamentals and applications," J. Phys., vol. 44, no. 28, p. 283001, 2011.

[28] K. M. Rajesh, B. Ajitha, Y. Ashok Kumar Reddy, Y. Suneetha, and P. Sreedhara Reddy, "Synthesis of copper nanoparticles and role of $\mathrm{pH}$ on particle size control," Mater. Today Proc., vol. 3, no. 6, pp. 1985-1991, 2016.

[29] K. Cheirmadurai, S. Biswas, R. Murali, and P. Thanikaivelan, "Green synthesis of copper nanoparticles and conducting nanobiocomposites using plant and animal sources," RSC Adv., vol. 4, no. 37, p. 19507, 2014.

[30]M. M. H. Khalil, E. H. Ismail, K. Z. El-Baghdady, and D. Mohamed, "Green synthesis of silver nanoparticles using olive leaf extract and its antibacterial activity," Arab. J. Chem., vol. 7, no. 6, pp. 1131-1139, 2014.

[31]L. S. B. Upadhyay and N. Kumar, "Green synthesis of copper nanoparticle using glucose and polyvinylpyrrolidone (PVP)," Inorg. Nano-Metal Chem., vol. 47, no. 10, pp. 1436-1440, 2017.

[32] M. S. Ghamsari, H. Mehranpour, and M. Askari, "Temperature effect on the nucleation and growth of $\mathrm{TiO}_{2}$ colloidal nanoparticles," Nanochem. Res., vol. 2, no. 1, pp. 132-139, 2017.

[33] M. Kumari, A. Mishra, S. Pandey, S P. Singh, V. Chaudry, M. K. R. Mudiam, S. Shukla, P. Kkkar, C. S. Nautiyal,., "Physico-chemical condition optimization during biosynthesis lead to development of improved and catalytically efficient gold nano particles," Sci. Rep., vol. 6, no. 27575 , pp. 1-14, 2016.

[34] J. Kumar, M. S. Akhtar, S. Ameen, P. Srivastava, and G. Singh, "Green synthesis of $\mathrm{CuO}$ nanoparticles with leaf extract of Calotropis gigantea and its dye-sensitized solar cells applications," J. Alloys Compd., vol. 632, pp. 321-325, 2015. 